Retrospective Study

\title{
e Nomogram for Predicting Intradiscal Cement Leakage Following Percutaneous Vertebroplasty in Patients with Osteoporotic Related Vertebral Compression Fractures
}

Bin-Yan Zhong, MD, Shi-Cheng He, MD, Hai-Dong Zhu, MD, Tao Pan, MD, Wen Fang, MD, Li Chen, MD, Jin-He Guo, MD, Gang Deng, MD, Guang-Yu Zhu MD, and Gao-Jun Teng, MD, PhD

From: Department of Radiology, Zhongda Hospital, Medical School, Southeast University, Nanjing, China

Address Correspondence: Gao-Jun Teng, MD, PhD Department of Radiology, Zhongda Hospital, Medical School, Southeast University, 87 Dingjiaqiao Rd Nanjing 210009, China Email: gjteng@vip.sina.com

Disclaimer: See pg ... Bin-Yan Zhong, Shi-Cheng $\mathrm{He}$, Hai-Dong Zhu, and Tao Pan contributed equally to the project.

Conflict of interest: Each author certifies that he or she, or a member of his or her immediate

family, has no commercial association (i.e., consultancies, stock ownership, equity interest, patent/licensing arrangements, etc.) that might pose a conflict of interest in connection with the submitted manuscript.

Manuscript received: 07-29-2016 Revised manuscript received: 09-18-2016

Accepted for publication: 11-21-2016

Free full manuscript: www.painphysicianjournal.com
Background: Intradiscal cement leakage (ICL) is a common complication following percutaneous vertebroplasty (PVP). However, the risk factors for such a complication are under debate and there is no accurate predictive nomogram to predict ICL.

Objectives: To establish an effective and novel nomogram for ICL following PVP in patients with osteoporotic-related vertebral compression fractures (OVCFs).

Study Design: This was a retrospective study approved by the Institutional Review Board of our institution.

Setting: This study consists of patients from a large academic center.

Methods: Patients with OVCFs who underwent their first PVP in our department between January 2007 and December 2013 were included in this study. All the potential risk factors of ICL after PVP were recorded. Univariate and multivariate analyses were used to identify the independent risk factors. The nomogram was then created based on the identified independent risk factors.

Results: A total of 241 patients and 330 vertebrae were included. The mean age of the patients was 73.5 (SD 7.9) years old, and the mean number of treated vertebrae was 1.4 per person. ICL was observed in $93(28.2 \%)$ of the treated vertebrae. Greater fracture severity $(P=0.016)$, cortical disruption of the endplate $(P<0.0001)$, absence of Kummell's disease $(P=0.010)$, and higher computed tomography $(C T)$ values $(P=0.050)$ were the independent risk factors for $\mathrm{ICL}$.

Limitations: The main limitation of this study is that it is a retrospective study.

Conclusion: Greater fracture severity, cortical disruption of the endplate, absence of Kummell's disease, and higher CT values are the independent risk factors for ICL. The novel nomogram gives an accurate prediction of $\mathrm{ICL}$.

Key words: Osteoporotic vertebral compression fracture, percutaneous vertebroplasty, intradiscal cement leakage, risk factors, prediction, nomogram

Pain Physician 2017; 20:E513-E520

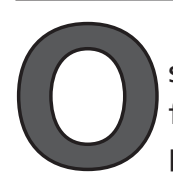

steoporotic-related vertebral compression fractures (OVCFs) are a common cause of pain and disability, with approximately 1.4 million new fractures occurring annually worldwide (1). First introduced in 1987 by Galibert et al (2), percutaneous vertebroplasty (PVP) has been regarded as an effective treatment approach. It is widely used to treat painful OVCFs. Past debate over the usefulness of this procedure (3-6) has been minimized by more recent and current studies which demonstrate the effectiveness of PVP for painful OVCFs $(4,7,8)$. 
As with any invasive procedure, PVP is also associated with asymptomatic and symptomatic complications (9). Severe complications, such as neurologic deficits (10), paraplegia (11), cardiac perforation $(12,13)$, and even death (14) have been reported. Many of these have been restricted to case reports. Cement leakage $(\mathrm{CL})$ is the most frequently occurring complication associated with PVP, having an incidence varying from $5 \%$ to more than $80 \%(8,15-17)$. With the use of computed tomography (CT), the incidence is estimated at $63 \%$ to $87 \%(8,16,18)$. Yeom et al $(18)$ divided $C L$ into 3 different types in a typical way, while Tome-Bermejo et al (19) modified it into the following 4 types: through the basivertebral vein (type B), the segmental vein (type S), a cortical defect (type C), and intradiscal leakage (type D). Each type of $\mathrm{CL}$ is asymptomatic under most conditions. However, several studies have demonstrated a symptomatic type of CL (20-22).

Intradiscal cement leakage (ICL) has been associated with each of the Tome-Bermejo categories in new adjacent and non-adjacent vertebral compression fractures. Pain with this leakage can reduce the quality of patients' lives (22-26). The risk factors for ICL are still under debate $(19,27-29)$. To date, there has been no effective nomogram to predict the risk of ICL. The purpose of this study is to identify the independent risk factors for ICL following PVP in patients with OVCFs. Our goal is to create a novel and effective nomogram able to accurately predict symptomatic ICLs in post PVP patients.

\section{Methods}

\section{Patient Criteria}

This retrospective cohort study was approved by the ethical review committees of our hospital. Patients with OVCFs who underwent their first PVP in our department between January 2007 and December 2013 were included in this study. Patients enrolled in this study met the following inclusion criteria: 1) acute VCFs from T5 to L5 based on the results of CT and magnetic resonance imaging (MRI) or CT and nuclear bone scan imaging if an MRI examination was contraindicated; 2) unrelieved, serious, and acute VCF-related focal spinal pain [defined as unrelieved by conservative therapy (analgesics, bed rest, and bracing) for at least 4 weeks]; 3) availability of complete imaging and medical record data; 4) age $\geq 55$ years; and 5) compliance with followups after the first treatment with PVP. The exclusion criteria were 1) any previous non-conservative treatments for VCFs; 2) PVP treatment for indications other than simple benign OVCFs; 3 ) incomplete imaging or medical record data; or 4) history of dementia, malignancy, or stroke (either before or after PVP).

\section{PVP Procedure}

All procedures were performed under local anesthesia using $2 \%$ lidocaine. PVP was performed under fluoroscopic guidance with a C-arm angiographic unit (Innova3100, GE Healthcare System or FD 20, Philips Medical) by 2 interventional radiologists (Gao-Jun Teng, Shi-Cheng $\mathrm{He}$ ) using a unilateral transpedicle approach with a Murphy set (Cook, Inc., Bloomington, Indiana). Each of the 2 operators had more than 10 years of experience performing PVP in a standard, reproducible way, assuring consistency in treatment between each of the patients. An additional puncture was performed (bilateral transpedicular approach) if the cement did not distribute as intended. The injected cement was a mixture of $70 \%$ polymethylmethacrylate (PMMA) (Corinplast TM3, Corin, Inc., Gloucestershire, United Kingdom) and $30 \%$ sterilized barium powder (Dongfeng Chemical, Inc., Qingdao, China). The cement was injected into the vertebral body during the "toothpaste-like" phase to minimize the risks of extravasation. Patients were restricted to absolute bed rest for about 2 hours following the procedure to assure the cement had reached its definitive strength. CT scanning of all patients was performed within 3 days after the PVP procedure to assess the distribution of PMMA and to determine the presence or absence of ICL.

\section{Radiographic Evaluation and Data Collection}

All the imaging data were retrospectively reviewed with a PACS system (NEUSOFTPACS/ RIS, Shengyang Neusoft Co., Ltd., China) by 2 radiologists, each having more than 5 years of diagnostic imaging experience (Shi-Cheng He, Hai-Dong Zhu). Disagreements between the 2 radiologists were resolved by consensus. Intradiscal cement leakage was defined as the presence of cement within the intervertebral disc via a vertebral endplate as assessed by post-procedural CT scanning (18).

The following patient data were recorded: age, gender, CT values of the spine, fracture type (wedge, biconcave, or crush), presence of pre-existing OVCFs, number of treated vertebrae, the location (thoracolumbar junction, non-thoracolumbar junction), severity of the vertebral body fracture, the presence of Kummell's disease, preoperative presence of endplate cortical defects, and cemented vertebral body fraction (CVBF, 
CVBF = ICVNVBV, where ICV is the volume of cement injected into the fractured vertebra and VBV is the vertebral body volume).

In this study, CT values were used to determine the degree of osteoporosis for each patient. The method of how to measure the $\mathrm{CT}$ values was introduced in our previously published study (25). According to Genant et al, (30) the severity of the treated vertebra was divided into 3 types, based on the percentage of vertebral body collapse, as either mild $(20 \%-25 \%)$, moderate $(26 \%-$ $40 \%$ ), or severe (> $40 \%$ ) fractures. Kummell's disease, named as an intravertebral cleft, was identified by the presence of gas within the vertebral body (by CT) or an intravertebral cleft based on plain anteroposterior and lateral radiographs. On MRI, Kummell's disease demonstrates low T1-weighted and high T2-weighted signal (fluid signal) associated with the vertebral cleft, producing the characteristic "double line sign" (31).

\section{Statistical Analysis}

Statistical analyses to identify risk factors were performed using SPSS 18.0 for Windows (IBM Corporation, Somers, NY, USA). Each potential risk factor was assessed using univariate logistic regression analysis. Variables that were significantly related to presence of ICL in the univariate analysis $(P<0.05)$ were subsequently included in a multivariate logistic regression analysis. A nomogram was formulated based on the results of multivariate analysis and by the package of rms in $\mathrm{R}$ version 3.0.2. A $P$ value of $<0.05$ was considered statistically significant.

\section{Results}

From January 2007 to December 2013, a total of 241 patients with 330 vertebral body fractures were included in this study. A majority of patients were women (187) and the mean age of the patients was 73.5 (7.9) years old, with mean CT bone mineral density values of 66.1 (34.7), which was an indication of a relative degree of osteoporosis in the majority of patients. Among the 330 treated vertebrae, $208(63.0 \%)$ of them were thoracolumbar vertebra and there were $83(25.2 \%), 114(34.5 \%)$, and $133(40.3 \%)$ vertebrae regarded as mild, moderate, and severe fracture, respectively. The detailed characteristics of the patients are described in Table 1.

Based on the post-operative CT, $93(28.2 \%)$ of the 330 treated vertebrae demonstrated an ICL. The clinical and radiological features of the $\mathrm{ICL}$ and non- $\mathrm{ICL}$ groups are shown in Table 2. After the univariate and multivariate analysis, greater fracture severity $(P=0.016)$, corti- cal disruption of the endplate $(P<0.0001)$, absence of Kummell's disease $(P=0.010)$, and higher CT values ( $P$ $=0.050$ ) were demonstrated as the independent risk factors for ICL (Table 3). Based on the 4 identified independent risk factors, a novel nomogram was created to assess the probability of incurring an ICL in a deterministic way (Fig. 1).

Furthermore, we assessed the new OVCFs occurring after PVP and their relationship with ICLs. We found that 85 new vertebral fractures occurred in 66 patients (27.4\%) during a follow-up of 924 (SD 654) days after the first PVP. Among them, 48 vertebrae (56.5\%) developed new VCFs adjacent to the treated vertebra, more than half of which (26 vertebrae) exhibited ICL. Our previous studies identified ICL as an independent risk factor for new OVCFs following PVP regardless of adjacent or non-adjacent status (25).

Table 1. Patient characteristics.

\begin{tabular}{|l|c||}
\hline No. patients & 241 \\
\hline Gender & $54(22.4 \%)$ \\
\hline Male & $187(77.6 \%)$ \\
\hline Female & $73.5(7.9)$ \\
\hline Age (Year) & $66.1(34.7)$ \\
\hline CT values (HU) & 330 \\
\hline No. treated vertebrae & $208(63.0 \%)$ \\
\hline TL junction & $122(37.0 \%)$ \\
\hline Non-TL junction & $175(53.0 \%)$ \\
\hline Fracture type & $121(36.7 \%)$ \\
\hline Wedge & $34(10.3 \%)$ \\
\hline Biconcave & $140(42.4 \%)$ \\
\hline Crush & $173(52.4 \%)$ \\
\hline Pre-existing vertebral fracture & $104(31.5)$ \\
\hline Number treated vertebrae per session \\
\hline 1 & $53(16.1 \%)$ \\
\hline 2 & $93(25.2 \%)$ \\
\hline$\geq 3$ & $114(34.5 \%)$ \\
\hline Fracture severity & $133(40.3 \%)$ \\
\hline 1 & $53(16.1 \%)$ \\
\hline 2 & $90(27.3 \%)$ \\
\hline 3 & $93(28.2 \%)$ \\
\hline Kummell's disease & \\
\hline Cortical disruption of the \\
endplate
\end{tabular}

Data are mean (SD) or number (\%). CT = computed tomography. HU $=$ Hounsfield unit. $\mathrm{TL}=$ thoracolumbar. 


\section{Discussion}

Cement leakage is the most common complication following PVP and can be divided into 4 types (19). Among them, ICL occurred frequently and is usually clinically asymptomatic. In addition, more

Table 2. Univariate analysis of risk factors for intradiscal cement leakage.

\begin{tabular}{|c|c|c|c|c|c|}
\hline Characteristic & ICL & No ICL & HR & 95\%CI & $P$-value * \\
\hline \multicolumn{6}{|l|}{ Gender } \\
\hline Male & 20 & 54 & 1 & & \\
\hline Female & 73 & 183 & 0.928 & $0.520-1.659$ & 0.802 \\
\hline \multicolumn{5}{|l|}{ Age (Years) } & 0.445 \\
\hline 1st Quartile $(<69)$ & 25 & 61 & 1 & & \\
\hline 2nd Quartile (69-73) & 25 & 66 & 1.460 & $0.708-3.011$ & 0.306 \\
\hline 3rd Quartile (74 - 78) & 27 & 53 & 1.349 & $0.656-2.774$ & 0.415 \\
\hline 4th Quartile ( $\geq 79)$ & 16 & 57 & 1.815 & $0.881-3.738$ & 0.106 \\
\hline \multicolumn{5}{|l|}{ CT values } & 0.044 \\
\hline 1st Quartile $(<40 \mathrm{HU})$ & 23 & 61 & 1 & & \\
\hline 2nd Quartile ( 40 - $63 \mathrm{HU})$ & 28 & 57 & 1.914 & $0.892-4.110$ & 0.096 \\
\hline 3rd Quartile (63 - $83 \mathrm{HU})$ & 29 & 53 & 2.494 & $1.181-5.265$ & 0.017 \\
\hline 4th Quartile ( $\geq 83 \mathrm{HU}$ ) & 13 & 66 & 2.778 & $1.316-5.866$ & 0.007 \\
\hline TL junction & 66 & 142 & 0.611 & $0.364-1.026$ & 0.063 \\
\hline \multicolumn{5}{|l|}{ Fracture type } & 0.469 \\
\hline 1 & 45 & 130 & 1 & & \\
\hline 2 & 36 & 85 & 0.635 & $0.291-1.386$ & 0.254 \\
\hline 3 & 12 & 22 & 0.776 & $0.347-1.735$ & 0.537 \\
\hline Preexisting fracture & 39 & 101 & 1.028 & $0.633-1.671$ & 0.910 \\
\hline \multicolumn{5}{|c|}{ Treated vertebra per session } & 0.418 \\
\hline 1 & 54 & 119 & 1 & & \\
\hline 2 & 25 & 79 & 1.264 & $0.634-2.521$ & 0.506 \\
\hline$\geq 3$ & 14 & 39 & 0.882 & $0.413-1.882$ & 0.745 \\
\hline \multicolumn{5}{|l|}{ Fracture severity } & 0.001 \\
\hline 1 & 23 & 60 & 1 & & \\
\hline 2 & 46 & 68 & 1.741 & $0.906-3.345$ & 0.096 \\
\hline 3 & 24 & 109 & 3.072 & $1.722-5.482$ & $<0.0001$ \\
\hline Kummell's disease & 27 & 26 & 0.301 & $0.164-0.552$ & $<0.0001$ \\
\hline \multicolumn{5}{|l|}{ CVBF } & 0.941 \\
\hline 1st Quartile $(<0.280)$ & 23 & 65 & 1 & & \\
\hline 2st Quartile $(0.280-0.369)$ & 22 & 56 & 0.908 & $0.461-1.786$ & 0.779 \\
\hline 3st Quartile $(0.370-0.481)$ & 25 & 57 & 1.008 & $0.506-2.008$ & 0.982 \\
\hline 4st Quartile ( $\geq 0.482)$ & 23 & 59 & 1.125 & $0.574-2.206$ & 0.731 \\
\hline $\begin{array}{l}\text { Cortical disruption of } \\
\text { endplate }\end{array}$ & 47 & 43 & 4.610 & $2.730-7.783$ & $<0.0001$ \\
\hline
\end{tabular}

${ }^{*}$ Univariate logistic regression analysis was used. The grouping of each parameter was based on the statistical meaning. ICL $=$ intradiscal cement leakage. $\mathrm{HR}=$ hazard ratio. $\mathrm{CI}=$ confidence interval. $\mathrm{CT}=$ computed tomography. $\mathrm{HU}=$ Hounsfield unit. $\mathrm{TL}=$ thoracolumbar. $\mathrm{CVBF}=$ cemented vertebral body fraction. and more studies are finding that ICL is associated with new adjacent OVCFs (22-26). Several studies have reported risk factors for ICL. Their findings such as the presence of Kummell's disease however, were inconsistent $(19,27,29)$. In our study, greater fracture severity $(P=0.016)$, cortical disruption of the endplate $(P<0.0001)$, absence of Kummell's disease $(P=0.010)$, and higher CT values $(P=0.050)$ were independent risk factors for ICL following PVP in patients with OVCFs.

In previous studies, Nieuwenhuijse et al (29) and Ding et al (27) reported that the presence of Kummell's disease was a risk factor for developing an ICL. They suggested that it was due to a frequently present connection between the intervertebral disc space and the intravertebral cleft $(27,29)$. However, Tome-Bermejo et al (19) took the opposite opinion. They concluded that the presence of the Kummell's disease was a protective factor limiting or preventing an ICL (19). They speculated that an intravertebral cleft represented the structure of least resistance within the bone $(19,32)$. Krauss et al (32) reported that the incidence of cement leakage was lower for fractured vertebral bodies with intravertebral clefts than for those without. Interestingly, Tanigawa et al (33) found that there was no statistical significance between the presence of an intravertebral cleft and an ICL. Our study demonstrated that the absence of Kummell's disease was an independent risk factor for development of an ICL. The presence of a necrotic cavity in the vertebral body promotes a more homogeneous and controlled filling of the fractured vertebral body, and the cement can be injected into the fractured vertebral body with lower pressure (19). As such, ICLs occur less often in the presence of Kummell's disease within the treated vertebral body.

Our study identified that cortical disruption of the endplate $(P<0.0001)$ and greater fracture severity $(P=0.016)$ are independent risk factors for ICL. These 2 risk factors have little controversy when referring to the prior published studies. Ding 
et al (27) conducted a retrospective study with 292 patients. They explored the risk factors for different types of $\mathrm{CL}$, and found that cortical disruption and greater fracture severity are strong risk factors for ICL (27). Tome-Bermejo et al (19) and Nieuwenhuijse et al (29) also reported similar results. Cortical disruption of the endplate provides a connection between the vertebral body and the intervertebral disc space, thereby providing a path of least resistance for the cement allowing it to leak into the intervertebral disc. The greater the fracture severity, the smaller the volume of the vertebral body. As such, the severely fractured vertebral body volume is insufficient to confine the injected cement. Therefore a severely fractured vertebral body has a greater probability of developing an ICL since it also has a greater chance of cortical disruption of an endplate.

Our study demonstrated that a higher CT value is an independent risk factor for ICL. Xie et al (28) found that patients with higher degree of osteoporosis had a lower chance of ICL. Bone mineral density (BMD) mea-
Table 3. Multivariate analysis of risk factors for intradiscal cement leakage.

\begin{tabular}{|c|c|c|c|c|}
\hline Variable & $\mathbf{B}$ & $\overline{\text { HR }}$ & 95\%CI & $P$-value* \\
\hline \multicolumn{4}{|c|}{ Cortical disruption of endplate } & $<0.0001$ \\
\hline 0 & 0 & 1 & & \\
\hline 1 & 1.579 & 4.852 & $2.761-8.527$ & \\
\hline \multicolumn{4}{|c|}{ Fracture severity } & 0.016 \\
\hline 1 & 0 & 1 & & \\
\hline 2 & 0.449 & 1.567 & $0.754-3.254$ & 0.229 \\
\hline 3 & 0.947 & 2.578 & $1.349-4.928$ & 0.004 \\
\hline \multicolumn{4}{|c|}{ Kummell's disease } & 0.010 \\
\hline 0 & 0 & 1 & & \\
\hline 1 & -0.898 & 0.407 & $0.206-0.806$ & \\
\hline \multicolumn{4}{|c|}{ CT values $(\mathrm{HU})$} & 0.050 \\
\hline$<40$ & 0 & 1 & & \\
\hline $40-63$ & 0.832 & 2.297 & $0.981-5.377$ & 0.055 \\
\hline $63-83$ & 1.024 & 2.783 & $1.210-6.401$ & 0.016 \\
\hline$\geq 83$ & 1.085 & 2.958 & $1.307-6.695$ & 0.009 \\
\hline
\end{tabular}

${ }^{*}$ Multivariate logistic regression analysis was used. HR = hazard ratio. $\mathrm{CI}=$ confidence interval. $\mathrm{CT}=$ computed tomography. $\mathrm{HU}=$ Hounsfield unit.

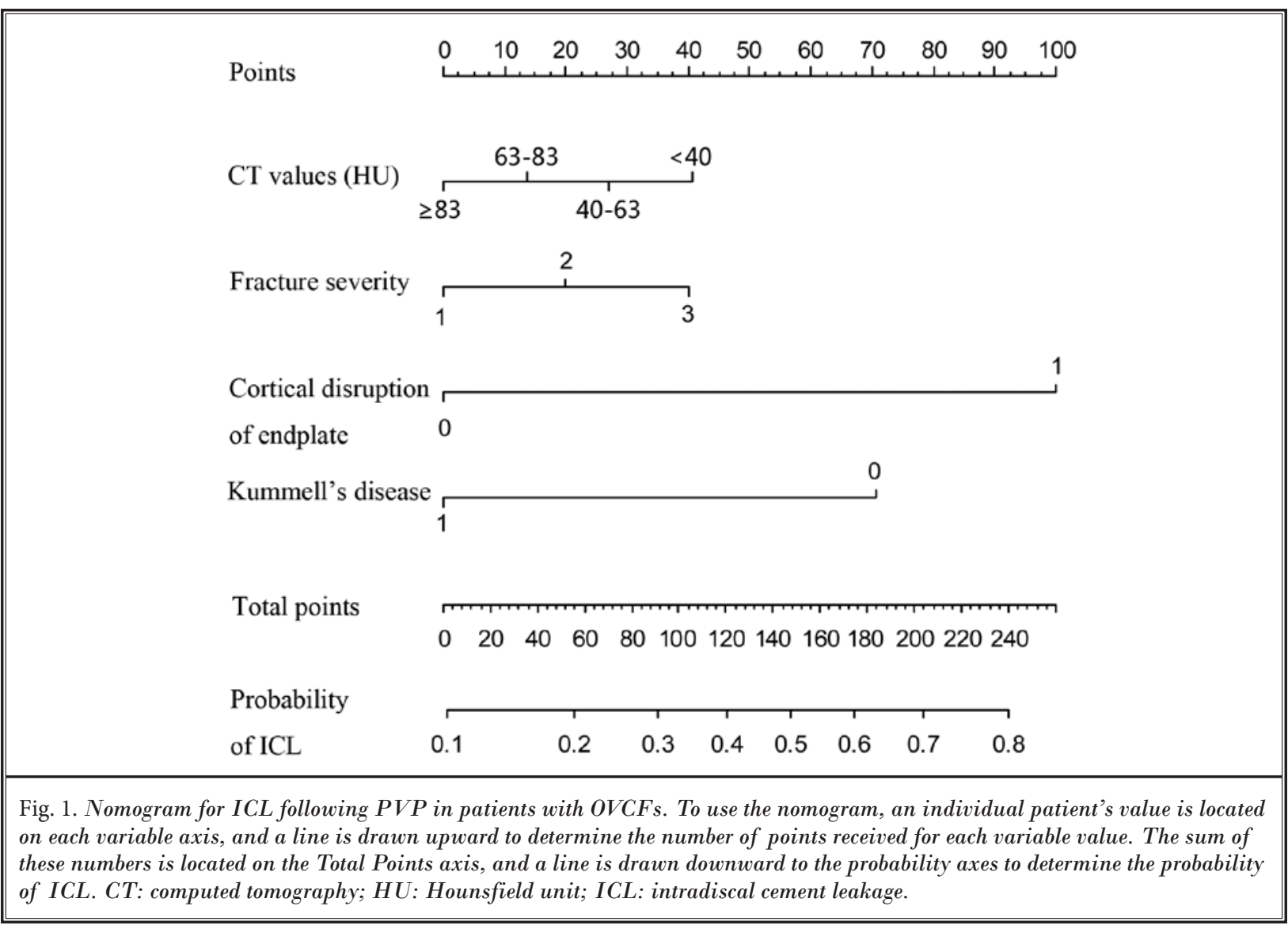


sured by dual energy $\mathrm{x}$-ray absorptiometry is a standard measurement for osteoporosis (34). However, the accuracy of BMD may be affected by several factors, such as spine degeneration and diffuse idiopathic skeletal hyperostosis, and will produce extra costs if additional BMD examinations are required $(35,36)$. Several previous studies showed that the CT values of the vertebrae correlate with BMD in osteoporotic patients $(35,37)$. Higher vertebral body CT values indicate a greater degree of trabecular bone per unit area and smaller spaces between the trabecular. As such, assuming the same dispersion rate and volume of PMMA, the smaller intertrabecular spaces would then require a greater area of cement spread (compared to an osteoporotic patient having larger intertrabecular spaces), thus increasing the risk of ICL (28).

Another frequently debated risk factor is injected cement volume. To assess the relationship between ICL and injected cement volume in treated vertebra with different volumes, we used the cemented vertebral body fraction (CVBF) parameter. In our study, CVBF is not a significant risk factor for ICL following PVP.

To our best knowledge, this study is the first attempt to predict the probability of ICL following PVP in patients with OVCFs by a novel nomogram. This method of creating a nomogram has been demonstrated as a reasonable, feasible approach in several disease models $(38,39)$. Referring to the prior studies, we are unable to calculate the probability of ICL through the identified risk factors. Instead, we can only speculate on the probability of ICL. With this nomogram, we are able to calculate the probability of an ICL with an accurate and easily preformed approach. Through the nomogram, the probability of ICL following PVP ranges from about $10 \%$ in patients with none of the independent risk factors to more than $80 \%$ in individuals with all 4 of the independent risk factors.

This direct assessment can guide a physician's procedural approach in efforts to prevent ICL. For example, if cortical endplate disruption is seen preoperatively (ICL risk of $35 \%$ ), the tip of the puncture needle could be directed away from the endplate fracture, or high viscosity cement could be deposited near the base of the fracture, and allowed to solidify, thereby blocking flow of the less viscous cement into the fracture, keeping it out of the disc space. Under circumstances of endplate fracture, physicians should inject the cement slowly and carefully under image guidance. With advanced frac- ture severity (Grade 3 ), the probability of $I C L$ is about $40 \%$. A preoperative CT scan with 3-D reconstruction will allow greater identification of area(s) of endplate disruption and allow for better preoperative planning. For those patients with a high probability of $\mathrm{ICL}$, percutaneous kyphoplasty (PKP) could be considered. PKP can provide a lower pressured space for cement deposition, similar to the theory behind Kummell's disease as being a protective factor for ICL.

Our study has a few limitations. First, as a retrospective study, there may be some degree of selection bias. A prospective study is warranted to validate the accuracy of our nomogram and to expound upon ICL risk factors using a stricter approach. Second, since we did not vary the viscosity of our cement (injected in a "tooth-paste" phase), we were not able to assess whether differing cement viscosities could be a risk factor for ICL. From the literature, we know viscosity is crucial for reducing the risk of PMMA cement leakage $(27,29,40)$. But, optimal cement viscosity is subjective, depending in part, on the experience of the surgeon (19). In our study, cement injection was performed during the "toothpaste-like" phase to minimize the risk of ICL.

\section{Conclusion}

In conclusion, our study demonstrated that a greater fracture severity, cortical disruption of the endplate, absence of Kummell's disease, and a higher BMD CT value are independent risk factors for developing $\mathrm{ICL}$ following PVP in patients with OVCFs. The novel nomogram we created objectively and accurately predicts the probability of an ICL. Further prospective studies are warranted to validate our nomogram.

\section{Funding}

This study was funded by the National Basic Research Program of China (973 Program \#2013CB733800, 2013733803), the National High-tech Research Foundation of China (863 project \#2012AA022701), the National Scientific and Technical Achievement Translation Foundation ([2012]258), the Jiangsu Provincial Special Program of Medical Science (BL2013029), and the National Natural Science Foundation of China (81230034, $81171434)$. Funding sources had no involvement in the financial support for the conduct of the research and preparation of the article. 


\section{References}

1. Johnell O, Kanis JA. An estimate of the worldwide prevalence and disability associated with osteoporotic fractures. Osteoporos Int 2006; 17:1726-1733.

2. Galibert P, Deramond $H$, Rosat P, Le Gars D. [Preliminary note on the treatment of vertebral angioma by percutaneous acrylic vertebroplasty]. Neurochirurgie 1987; 33:166-168.

3. Smieliauskas F, Lam S, Howard DH. Impact of negative clinical trial results for vertebroplasty on vertebral augmentation procedure rates. J Am Coll Surg 2014; 219:525-533, e521.

4. Klazen CA, Lohle PN, de Vries J, Jansen $\mathrm{FH}$, Tielbeek AV, Blonk MC, Venmans A, van Rooij WJ, Schoemaker MC, Juttmann JR, Lo TH, Verhaar HJ, van der Graaf $Y$, van Everdingen KJ, Muller AF, Elgersma OE, Halkema DR, Fransen $H$, Janssens X, Buskens E, Mali WP. Vertebroplasty versus conservative treatment in acute osteoporotic vertebral compression fractures (Vertos II): An openlabel randomised trial. Lancet 2010; 376:1085-1092.

5. Buchbinder R, Osborne RH, Ebeling PR, Wark JD, Mitchell P, Wriedt C, Graves S, Staples MP, Murphy B. A randomized trial of vertebroplasty for painful osteoporotic vertebral fractures. $N$ Engl ] Med 2009; 361:557-568.

6. Kallmes DF, Comstock BA, Heagerty PJ, Turner JA, Wilson DJ, Diamond TH, Edwards R, Gray LA, Stout L, Owen S, Hollingworth W, Ghdoke B, AnnesleyWilliams DJ, Ralston SH, Jarvik JG. A randomized trial of vertebroplasty for osteoporotic spinal fractures. N Engl J Med 2009; 361:569-579.

7. Kroon F, Staples M, Ebeling PR, Wark JD, Osborne RH, Mitchell PJ, Wriedt $\mathrm{CH}$, Buchbinder R. Two-year results of a randomized placebo-controlled trial of vertebroplasty for acute osteoporotic vertebral fractures. J Bone Miner Res 2014; 29:1346-1355.

8. Clark W, Bird P, Gonski P, Diamond TH, Smerdely P, McNeil HP, Schlaphoff G, Bryant C, Barnes E, Gebski V. Safety and efficacy of vertebroplasty for acute painful osteoporotic fractures (VAPOUR): A multicentre, randomised, double-blind, placebo-controlled trial. Lancet 2016 [Epub ahead of print].

9. Lee MJ, Dumonski M, Cahill P, Stanley T, Park D, Singh K. Percutaneous treatment of vertebral compression fractures: A meta-analysis of complications.
Spine (Phila Pa 1976) 2009; 34:1228-1232.

10. Patel AA, Vaccaro AR, Martyak GG, Harrop JS, Albert TJ, Ludwig SC, Youssef JA, Gelb DE, Mathews HH, Chapman JR, Chung EH, Grabowski G, Kuklo TR, Hilibrand AS, Anderson DG. Neurologic deficit following percutaneous vertebral stabilization. Spine (Phila Pa 1976) 2007; 32:1728-1734.

11. Bhide RP, Barman A, Varghese SM, Chatterjee A, Mammen S, George J, Thomas R. A rare presentation of subacute progressive ascending myelopathy secondary to cement leakage in percutaneous vertebroplasty. Am J Phys Med Rehabil 2014; 93:431-436.

12. Son KH, Chung JH, Sun K, Son HS. Cardiac perforation and tricuspid regurgitation as a complication of percutaneous vertebroplasty. Eur J Cardiothorac Surg 2008; 33:508-509.

13. Moon $\mathrm{MH}$, Jo KH, Kim HW. Cardiac perforation caused by bone cement embolism. Arch Cardiovasc Dis 2013; 106:413-414.

14. Monticelli F, Meyer HJ, Tutsch-Bauer E. Fatal pulmonary cement embolism following percutaneous vertebroplasty (PVP). Forensic Sci Int 2005; 149:35-38.

15. Hulme PA, Krebs J, Ferguson SJ, Berlemann U. Vertebroplasty and kyphoplasty: A systematic review of 69 clinical studies. Spine (Phila Pa 1976) 2006; 31:1983-2001.

16. Schmidt R, Cakir B, Mattes T, Wegener M, Puhl W, Richter M. Cement leakage during vertebroplasty: An underestimated problem? Eur Spine ] 2005; 14:466-473.

17. Muijs SP, Nieuwenhuijse MJ, Van Erkel AR, Dijkstra PD. Percutaneous vertebroplasty for the treatment of osteoporotic vertebral compression fractures: Evaluation after 36 months. J Bone Joint Surg Br 2009; 91:379-384.

18. Yeom JS, Kim WJ, Choy WS, Lee CK, Chang BS, Kang JW. Leakage of cement in percutaneous transpedicular vertebroplasty for painful osteoporotic compression fractures. J Bone Joint Surg Br 2003; 85:83-89.

19. Tome-Bermejo F, Pinera AR, Duran-Alvarez C, López-San Román B, Mahillo I, Alvarez L. Identification of risk factors for the occurrence of cement leakage during percutaneous vertebroplasty for painful osteoporotic or malignant vertebral fracture. Spine (Phila Pa 1976) 2014. [Epub ahead of print]
20. Venmans A, Klazen CA, Lohle PN, van Rooij WJ, Verhaar HJ, de Vries J, Mali WP. Percutaneous vertebroplasty and pulmonary cement embolism: Results from VERTOS II. AJNR Am J Neuroradiol 2010; 31:1451-1453.

21. Kim YJ, Lee JW, Park KW, Yeom JS, Jeong HS, Park JM, Kang HS. Pulmonary cement embolism after percutaneous vertebroplasty in osteoporotic vertebral compression fractures: Incidence, characteristics, and risk factors. Radiology 2009; 251:250-259.

22. Chen WJ, Kao YH, Yang SC, Yu SW, Tu YK, Chung KC. Impact of cement leakage into disks on the development of adjacent vertebral compression fractures. J Spinal Disord Tech 2010; 23:35-39.

23. Martinez-Ferrer A, Blasco J, Carrasco JL, Macho JM, Román LS, López A, Monegal A, Guañabens N, Peris P. Risk factors for the development of vertebral fractures after percutaneous vertebroplasty. J Bone Miner Res 2013; 28:1821-1829.

24. Nieuwenhuijse MJ, Putter $H$, van Erkel AR, Dijkstra PD. New vertebral fractures after percutaneous vertebroplasty for painful osteoporotic vertebral compression fractures: A clustered analysis and the relevance of intradiskal cement leakage. Radiology 2013; 266:862-870.

25. Zhong BY, Wu CG, He SC, Zhu HD, Fang W, Chen L, Guo JH, Deng G, Zhu GY, Teng GJ. ANVCFV Score System: Assessment for probability of new vertebral compression fractures after percutaneous vertebroplasty in patients with vertebral compression fractures. Pain Physician 2015; 18:E1047-E1057.

26. Ahn Y, Lee $\mathrm{JH}$, Lee HY, Lee $\mathrm{SH}$, Keem $\mathrm{SH}$. Predictive factors for subsequent vertebral fracture after percutaneous vertebroplasty. J Neurosurg Spine 2008; 9:129-136.

27. Ding J, Zhang Q, Zhu J, Tao W, Wu Q, Chen L, Shi P, Zhang H. Risk factors for predicting cement leakage following percutaneous vertebroplasty for osteoporotic vertebral compression fractures. Eur Spine ] 2016; 25:3411-3417.

28. Xie W, Jin D, Ma H, Ding J, Xu J, Zhang $\mathrm{S}$, Liang D. Cement leakage in percutaneous vertebral augmentation for osteoporotic vertebral compression fractures: Analysis of risk factors. Clin Spine Surg 2016; 29:E171-E176.

29. Nieuwenhuijse MJ, Van Erkel AR, Dijkstra PD. Cement leakage in percutaneous vertebroplasty for osteoporotic vertebral 
compression fractures: Identification of risk factors. Spine ] 2011; 11:839-848.

30. Genant HK, Wu CY, van Kuijk C, Nevitt MC. Vertebral fracture assessment using a semiquantitative technique. J Bone Miner Res 1993; 8:1137-1148.

31. Maldague BE, Noel HM, Malghem JJ. The intravertebral vacuum cleft: A sign of ischemic vertebral collapse. Radiology 1978; 129:23-29.

32. Krauss M, Hirschfelder H, Tomandl B, Lichti G, Bär I. Kyphosis reduction and the rate of cement leaks after vertebroplasty of intravertebral clefts. Eur Radiol 2006; 16:1015-1021.

33. Tanigawa N, Kariya S, Komemushi A Tokuda T, Nakatani M, Yagi R, Sawada $\mathrm{S}$. Cement leakage in percutaneous vertebroplasty for osteoporotic compression fractures with or without intravertebral clefts. AJR Am J Roentgenol 2009; 193:W442-W445.
34. Briot K. DXA parameters: Beyond bone mineral density. Joint Bone Spine 2013; 80:265-269.

35. Schreiber JJ, Anderson PA, Rosas HG, Buchholz AL, Au AG. Hounsfield units for assessing bone mineral density and strength: A tool for osteoporosis management. J Bone Joint Surg Am 2011; 93:1057-1063.

36. Westerveld LA, Verlaan JJ, Lam MG, Scholten WP, Bleys RL, Dhert WJ, Oner FC. The influence of diffuse idiopathic skeletal hyperostosis on bone mineral density measurements of the spine. Rheumatology (Oxford) 2009; 48:1133-1136.

37. Link TM, Koppers BB, Licht T, Bauer J, Lu Y, Rummeny EJ. In vitro and in vivo spiral CT to determine bone mineral density: Initial experience in patients at risk for osteoporosis. Radiology 2004; 231:805-811.
38. Karakiewicz PI, Briganti A, Chun FK, Trinh QD, Perrotte P, Ficarra V, Cindolo L, De la Taille A, Tostain J, Mulders PF, Salomon L, Zigeuner R, Prayer-Galetti $\mathrm{T}$, Chautard D, Valeri A, Lechevallier E, Descotes JL, Lang H, Mejean A, Patard J. Multi-institutional validation of a new renal cancer-specific survival nomogram. J Clin Oncol 2007; 25:1316-1322.

39. Xu L, Peng ZW, Chen MS, Shi M, Zhang YJ, Guo RP, Lin XJ, Lau WY. Prognostic nomogram for patients with unresectable hepatocellular carcinoma after transcatheter arterial chemoembolization. J Hepatol 2015; 63:122-130.

40. Baroud G, Crookshank M, Bohner M. High-viscosity cement significantly enhances uniformity of cement filling in vertebroplasty: An experimental model and study on cement leakage. Spine (Phila Pa 1976) 2006; 31:2562-2568. 